\title{
The problem with thalidomide's new incarnation
}

The US Food and Drug Administration's (FDA) approval of thalidomide for the treatment of Hansen's disease- once called leprosyshows just how government and industry can work together to bring back to market a drug that, while infamous for the terrible birth defects it produced when taken to relieve the symptoms of morning sickness by unsuspecting women, evidently does have significant beneficial uses. But with only about 1000 Hansen's disease patients currently living in the United States, and 2000 physicians and 2000 pharmacies currently slated to be trained in the use of thalidomide, the ambitions of Celgene-the manufacturer of the new versions of thalidomide-appear larger than the uses that will be specified on the drug's label.

Among the major markets that Celgene seems to be aiming at are those of the considerable number of AIDS and cancer patients who could benefit from the drug. The mouth ulcers and wasting diseases of AIDS and brain and breast tumors are not yet approved indications for thalidomide treatment. Are these among the main life-threatening indications for which the drug will be used? If so, is it not dubious to approve a drug for one indication with the unsubtle implied intent of encouraging its off-label use in others?

One part of the problem, as the Tufts University Center for the Study of Drug Development has been pointing out for years, is that the approval process for new indications for old drugs is notoriously slow and complex-sometimes taking longer than the approval process for the original new drug approval itself. And after a drug is approved, the sponsoring company bears little or no responsibility for its off-label use.

The burden thus lies with the prescribing physicians, who are in effect conducting their own clinical trials in deciding what patients to treat for what reasons. They also decide, in any compliance monitoring, what reasons to list for providing treatment. Health insurance providers are, by and large, not obligated to pick up the cost off-label drug use. Does this mean then that the reported number of Hansen's disease patients living in the United States will increase 200 -fold in the coming year?

If the whole idea of approving thalidomide was to bring it into legal usage and out of the black market Internet buyers' domain (or to keep patients from having to go to Mexico and Brazil to pick up what they need), why not finish the job and redouble efforts to approve this drug for its many supplemental indications quickly? We encourage the FDA - and the US Congress-to complete the task of FDA modernization. Revise supplemental new drug applications to make them the prevailing practical mode of accountability-not offlabel, off the-record, experimentation. The dead off-label prescription users of any number of drugs would thank you for doing so, if only they could.

\section{Jeremy Rifkin is biotechnology's biggest fan}

Extreme fans are fanatics. And if we ventured the opinion that Jeremy Rifkin was fanatical when it came to biotech, few would disagree. But Rifkin's fanaticism is not, at least yet, of the variety that borders on lunacy. Quite the contrary, his deep passion for biotechnology is reflected by generally reasoned and often articulate arguments that display an impressive breadth (if not always depth) of reading and thinking about the historical relationships between social change and technology. Indeed Rifkin's fanaticism is more akin to that of an avid and knowledgeable sports fan, because above all else, Jeremy Rifkin believes.

Nowhere is this more apparent than in his most recent book, Harnessing the Gene and Remaking the World, The Biotech Century, it's very title appropriating Wall Street's futuristic hyperbole, and its final chapters Computing DNA and Reinventing Nature, containing copy that the most enthusiastic biotechnology PR firm would shy away from issuing. Writing of the brave new world of genomics, for example, he offers remarks that have to gladden the hearts of company executives and their investment bankers.

Mapping and sequencing the genomes is just the beginning. Reorganizing the whole of the natural world at the genetic level, with an eye to converting it to an array of useful commodities in the marketplace, is a daunting challenge, and easily the greatest management task ever conceived (p. 189).

or even better:

The final integration of the information and life sciences comes in the form of the "molecular computer." . . DNA supercomputers will run a million times faster than today's most advanced super- computer, and fundamentally change the way we live and the kind of world we live in. The DNA supercomputer brings the information sciences and the life sciences together into a single technological revolution, with the power to remake the world (pp. 192-193).

And although clearly recognizing that the linguistic commonalties between molecular biology and information sciences are only metaphors, and that the cell, much less a conscious organism, is not reducible to a series of DNA embedded, chemical software routines, no matter how intriçate, Rifkin cannot help himself from echoing the promises of biotech's most wide-eyed prophets.

The biotech revolution is, after all, the ultimate consumer playground, offering $u$ s the freedorn to recast our own biological endowment and the rest of nature to suit whatever whim might move us. More important, the new genetic technologies grant us a godlike power to select the biological futures and features of the many beings who come after us (p. 223).

It is hard to imagine a more devout fan than this, and it makes little difference that such rapture is loosely surrounded by its troubling implications for a society that is so woefully ignorant of real biology that it devotes high-toned national evening news programs to "serious" discussions between otherwise respected scientists on the possibility of resurrecting extinct species from fossilized DNA. But the same Hollywood that made Jurassic Park has also produced another genre of film that should give us pause before we become too carried away with the notion of Rifkin as biotech proselytizer. Fans, let us not forget, can also be dangerous. 